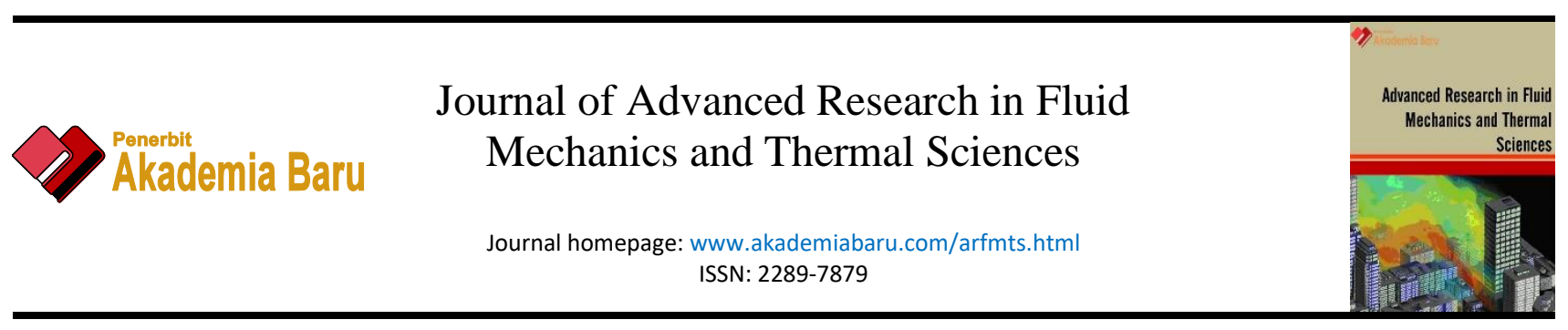

\title{
Temperature Dependence on Silver Conductivity and Adhesion Performance Between Silver and Flexible Substrate
}

\author{
Afiqah Mohd Yunos ${ }^{1}$, Ghazali Omar ${ }^{1,2,3,}{ }^{*}$, Mohd Azli Salim ${ }^{1,2,3}$, Nor Azmmi Masripan ${ }^{1,2}$, Bunyemin \\ Cosut $^{4}$, Ahmad Faris Mohd Adnan ${ }^{5}$
}

1 Faculty of Mechanical Engineering, Universiti Teknikal Malaysia Melaka, Hang Tuah Jaya, 76100 Durian Tunggal, Melaka, Malaysia

2 Centre for Advanced Research on Energy, Faculty of Mechanical Engineering, Universiti Teknikal Malaysia Melaka, Hang Tuah Jaya, 76100 Durian Tunggal, Melaka, Malaysia

3 Advanced Manufacturing Centre, Universiti Teknikal Malaysia Melaka, Hang Tuah Jaya, 76100 Durian Tunggal, Melaka, Malaysia

4 Department of Chemistry, Gebze Institute of Technology, 41400 Kocaeli, Turkey

5 Institute of Biological Sciences, Faculty of Sciences, University of Malaya, 50603 Kuala Lumpur, Malaysia

\section{ARTICLE INFO $\quad$ ABSTRACT}

\section{Article history:}

Received 11 January 2020

Received in revised form 4 May 2020

Accepted 4 May 2020

Available online 31 July 2020
Printed circuit board (PCB) is the main component in almost all electronic devices. The increase in the demand for PCB cause dramatically increases of E-waste. The improper discard practice of printed circuit board (PCB) leads to human health and environmental problems. Although the study had been done to improve the recycling process of E-waste, awareness from various parties needs more effort for this improved recycling process to successfully implement. Therefore, an alternative way by substitute the conventional PCB with the new flexible PCB can help eliminate these issues. The basic design of a flexible PCB consists of a flexible base and conductor. However, a key point during the developing of this new technology is the adhesion between the flexible base and conductor, which thermoplastic polyurethane (TPU) as the base, while silver as the conductor was used throughout this study. This paper presents the effect of temperature in improving adhesion between substrate and silver, and concurrently influence the electrical conductivity of silver conductor. In this study, the characterization of silver and substrate respected to temperature individually analysed, followed by the qualitative adhesion observation between silver and substrate was carried out through cross-cut test according to ASTM D3359-09. The silver was exposed to different curing temperatures exhibit lower sheet resistance when temperature increase. Meanwhile, the substrate exposed to a temperature higher than glass transition $\left(\mathrm{T}_{\mathrm{g}}\right)$ increases improve the adhesion between silver and substrate.
Keywords:

Adhesion; silver; polymer

\footnotetext{
* Corresponding author. E-mail address: ghazali@utem.edu.my
}

https://doi.org/10.37934/arfmts.73.2.7387 


\section{Introduction}

Nowadays, improper electronic waste (E-waste) management globally has been drawing environmental and social concerns as they reported to create a threat toward public health and the environment [1-4]. According to the Global E-waste Monitor, in 2016 it reported the continuity grows of the waste amount exceed the recycled one by 44.7 million metric tonnes and expected to gradually increase to 52.2 million metric tonnes by 2021 [5]. Besides that, estimation on the global level made by UN Environment Programme indicates, the amount of E-waste dramatically rises three times faster than other forms of municipal waste by generating 20-50 million tonnes per annual [6]. This serious upstream of e-waste is due to the urbanization and industrialization events that consume large amounts of electrical and electronic equipment (EEE) [4,7].

Generally, printed circuit boards (PCBs) are integral core components must-have in almost all EEE, with percentage varies between 3\% to 6\% [8]. Accordance to IPC's World PCB Production Report, PCB industry achieved an estimated real growth of $13.9 \%$ in 2017. China reported dominating more than half of the world's production value (52.7\%) [9]. Reviewed done by Huang et al., [7] stated, the presence of advanced technology as well as intense marketing in China cause a rapid update rate of EEE and shorten the average lifespan. Therefore, lead to dramatically increasing E-waste number [7].

Besides that, further discussion was made on the components exist in the waste PCBs. They comprise of brominated flame retardants (BFR), PVC plastic and heavy metals. Due to these components, improper discarded activities can generate hazardous byproducts such as dioxins, furans, polybrominated organic pollutants and polycyclic aromatic hydrocarbons, and worse if the leaching events into groundwater or soil is happening [7].

Environmental policies like Directive 2002/96/EC of the European Union (EU) for all EU member states established to ensure End-of-Life recovery system operated for e-waste recovery and similar legislation been adopted in non-EU member states [10-13]. Moreover, end destiny of all e-wastes controlled according to The Basel Convention of 1989 that designed to minimize the transboundary globalization movement of hazardous waste and intended to ensure environmentally sound management through reduction of generated waste by parties [14,15]. All the mentioned environmental policies had been imposed globally on the waste of electrical and electronic equipment (WEEE) for restricting simply disposal practices to non-Organization for Economic Cooperation and Development (OECD) countries, yet the fate of e-waste streams end up towards cheap waste disposable sites abroad (China, India and West Africa) cause the sustainable objective impossible to achieved [14]. Since a few years ago, recycling and recovery movement had been part of the solution in the management of E-waste at a global level. However, reuse and recycling printed circuit board (PCB) faced difficulties in separation of the components and materials, due to the variety of attached components to serve their functions in the appliances. These electronic components need to be separated from the solder for reuse purpose involved complex process and applied of temperature during dissembling make components impossible to be reuse. Although these improvements for recycling process purposed promising much efficient and less complicated operation, but the implementation of this recycling process still depending on awareness from various parties such as industrial and also consumer and also need more effort to be implemented, therefore continuity push for better solution by another alternative to substitute the traditional PCB is the best way to prevent any continuous harming activities toward environment.

Effective alternatives to replaced PCB had been catch attention among the researchers. The most promising alternative is by the introduction of flexible PCB. Flexible printed circuit holds a meaning which is it comprises of a patterned arrangement of printed circuit and components on the flexible base material as substrate and flexible cover lay as an option (IPC, 1996). According to the trend 
among consumers, further progress in electronic manufacture driving towards miniaturization and the most recent research focusing on the production of thin and flexible electronics. As consumer prefer high durability and long-term performance in the products, $[16,17]$ studied by Coombs \& Holden stated that rigid or traditional boards will be replaced by flexible printing boards in a variety of electronic device [18]. Flexible printing circuit board (Figure 1) made up of distinct materials which are

- Base material (dielectric film/ flexible substrate)

- Conductor (foil/conductive coating)

- Adhesive (optional)

- Cover lay (film/ coating)

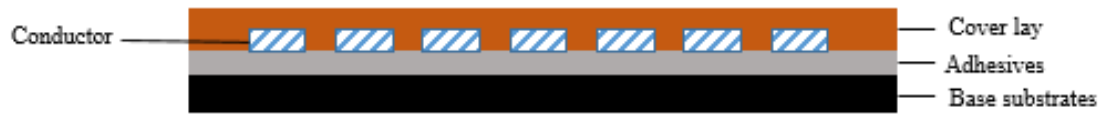

Fig. 1. Illustration of flexible printing circuit board design [19]

The stretchable conductive paste is the ideal conductor material used to fabricate a flexible printed circuit board. They had been studied extensively by the previous researcher, which can be implemented in electronic, resulting in the desired stretchable trait [20-22]. Generally, a combination of three different groups, which are conductive filler, polymer binder, and volatile and non-volatile organic polymer, will develop ready-to-use stretchable conductive ink [23]. Conductive filler had been extensively studied for example carbonous-based material (such as graphene [24], carbon nanotube (CNT) [25] and metallic material (such as copper [26,27], silver $[22,28,29]$ ). For this study, silver was chosen due to amongst all the conductive fillers, silver exhibit robust and excellent conductivity with sheet resistance typically $0.01-0.04 \Omega / \mathrm{sq}$ at dry thickness $25 \mu \mathrm{m}$ of ink layer [22] as well as have good chemical durability [28]. Prior application of paste in the printing process, specific parameters need to be considered in metal paste: diameter size, fluidity (viscosity), surface tension and wettability [30]. Nanoparticle or nanometer size of the filler material is attractive features as allowed it to formulate easily into various inks and paste, therefore it can be applied by various printing methods. Generally, the metal ink or paste comprises a small diameter size of the particle as the size affected melting temperature as they related to surface energy of the particles. The energy state of atoms is higher on the surface compared than inside the crystalline body effect of daggling bonds on the material surface. Hence, the smaller the particle size, the higher the surface energy, thus the particles said to be in high energy state [31]. This also supported by the study on the effect of size on the melting point by using electron diffraction by Buffet and Borel [32]. As the particle gets smaller, the lower the melting temperature will be compared than the bulk metal as the atomic diffusion is said to more active in nanoparticles near the surface [31,33,34]. Hence, proper selection of metal filler based on the diameter is important, a wider range of metal ink application on substrate preferring lower post-curing temperature. Another component should have in fabricating conductive metal paste is polymer binder which plays an essential role by holding the conductive filler within the matrix and serve to adhered ink to the substrate, while offering stretchability properties in ink upon the curing process. While the solvent act as a carrier by providing viscosity element for the ink to be printable.

Another material required as part of flexible printed circuit board is flexible base material or substrate. There are widen interest of research on several types of flexible substrates, for instance, paper, polymer, and textile, which all of them not restricted only for industrial applications but also medical purposes $[35,36]$. Non-reinforced polymer promising more economic-friendly in terms of the fabrication process and maintaining flexible property. These properties allowed larger study areas of 
intelligent PE applications so that they can applied in the complex system and environment [37]. In addition, criteria of a substrate including low cost, abundantly available, flexible, chemical resistance and stable in high dimension as well as compatible for a broader range of formulated ink made it favored among the industries. Different types of polymer had been used as substrate material in PE application, for example, thermoplastic polyurethane [38,39], PDMS [40-43] and polyurethane [42] due to their desired properties which is flexible and extensible. Thermoplastic polyurethane (TPU) with low elastic modulus and high stretchability was chosen as the substrate in this study.

However, key issues that arise in the development of printed electronics technology is the adhesion compatibility between the conductive layer and substrate that need further improvement [43-45]. Better adhesion strength required for the end application become more reliable and durable against mechanical stress that generally will reduce defects such as porosity and cracks. Besides that, poor adhesion between silver and underlayer substrate also causes the heat to inefficiently dissipate when the current pass through within silver conductive film hence, create more resistance that leads into poor conductivity performance of silver. The adhesiveness performance of metallic thin film influence by the temperature had studied since 1992 [44]. This adhesion-enhancing technique considered as a conventional technique that keeps been studied until today as this attempted markedly improved adhesiveness of printed conductive ink $[43,45,46]$. This technique also claimed as a one-step achievement for having excellent in both electrical conductivity and adhesiveness that can be controlled by the total of heat exposure [46]. Although many authors have conducted studies on the adhesiveness of metallic thin film on different polymers such as poly(4-vinyl phenol) (PVP), poly(methyl methacrylate) (PMMA), Teflon and polyethyleneterephthalate (PET) [43,45-47], however to our knowledge, there are still lack in the exploration of this technique specifically on thermoplastic polyurethane (TPU). TPU considered as a highly versatile polymer that provides superior performance and flexibility, which make it abundantly available within the market for different applications. But, exploration on TPU as underlayer substrate is not widely studied mainly in the fabrication of flexible printed circuit due to the narrow temperature range of processing as well as possess hydrophobic nature and low surface energy. Hence, to address this issue, the dependence of temperature in improving adhesion between silver and TPU underlayer as well as silver conductivity were investigated.

\section{Methodology}

\subsection{Test Samples and Patterns}

Thermoplastic polyurethane (TPU) was supplied from Takeda Sangyo and used as-received. Material has a thickness of $100 \mu \mathrm{m}$ with an optically transparent polyester film. Screen printing was executed to print conductive silver ink pattern on the TPU with a dimension of $7 \mathrm{~cm}$ length $x 7 \mathrm{~cm}$ width. The substrate was clean first with ethanol to eliminate any contamination on the surface before printing conducted. The commercial conductive silver paste was used in this study. The posttreatment step was conducted by curing in the oven at various temperature: (1) room temperature, (2) $60^{\circ} \mathrm{C}$, (3) $80^{\circ} \mathrm{C},(4) 100^{\circ} \mathrm{C},(5) 120^{\circ} \mathrm{C}$, (6) $130^{\circ} \mathrm{C}$ and (7) $140^{\circ} \mathrm{C}$. The prepared test pattern of silver is presented in Figure 2. 


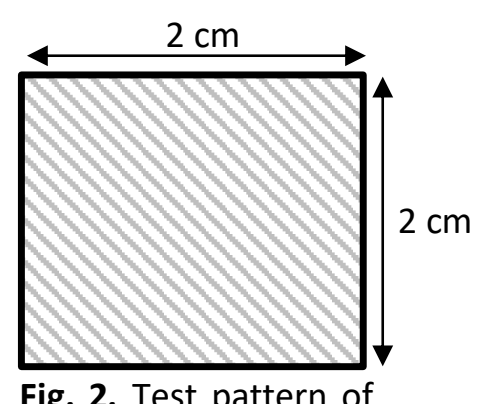

Fig. 2. Test pattern of printed silver on TPU substrate

\subsection{Characterization of Silver}

\subsubsection{Resistivity measurement}

The electrical resistivity of silver after curing at different temperatures was measured to investigate the effect of temperature on the conductivity of silver. Measurement was done by fourpoint probe measurement (Jandel RM3000). The current supplied was fixed to $100 \mathrm{~mA}$, and sheet resistance was measured on 6 different points to ensure reliable reading. The sheet resistance is measure according to the Eq. (1).

$R_{\text {square }}=c f \times \frac{V}{I}$

where $c f$ is a correction factor that was assumed to be 4.53. $V$ is the voltage between the inner probe, and $I$ is the current supplied.

\subsubsection{Microstructure analysis}

Scanning electron microscopy (SEM) was used to observe the microstructure behaviour of the silver paste respected to temperature. The micrograph of SEM was acquired with JEOL JSM6010PLUS/LV at an accelerated voltage of 10kV. Energy Dispersive X-Ray Analysis (EDX) was carried out on silver paste at room temperature (Figure 3). EDX spectrum of silver paste indicates a silver content of 21.43 atom \% followed by $\mathrm{O}$ (16.04 atom \%) and $\mathrm{Cl}$ (4.34 atom \%).

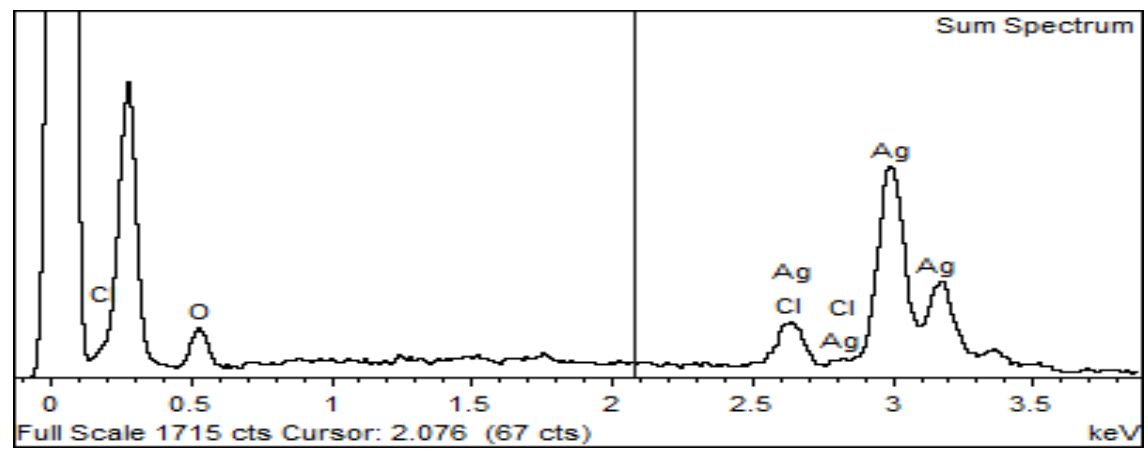

Fig. 3. EDX spectrum of silver paste 


\subsection{Characterization of Substrate}

\subsubsection{Differential Scanning Calorimetry (DSC) analysis}

The heating properties of the substrate were characterized by DSC analysis (DSC Perkin Elmer S400 instrument). Heating and cooling were conducted at rate $10^{\circ} \mathrm{C} \mathrm{min}{ }^{-1}$ with a sample mass of $6.21 \mathrm{mg}$ capped in the TA $\mathrm{T}_{\text {zero }}$ aluminium pans. The sample was loaded at room temperature and cooled to $-40^{\circ} \mathrm{C}$. Heating was performed up to $300^{\circ} \mathrm{C}$ and followed by subsequently cooling.

\subsubsection{Surface energy analysis}

The surface energy of the substrate was measured at different curing temperatures. The surface energy for the TPU was calculated by Owen-Wendt method, which involved two components of surface energy theories. For this analysis, water and $n$-hexane were used as test fluids, and their contact angle was used to measure the water and oil repellences, respectively. Table 1 represents the surface tension of water and $n$-hexane.

Table 1

Surface Tension Components

\begin{tabular}{lllll}
\hline Liquid & $\gamma \mathrm{Lv}, \mathrm{mN} / \mathrm{m}$ & $\gamma^{\mathrm{p}} \mathrm{sv}, \mathrm{mN} / \mathrm{m}$ & $\gamma^{\mathrm{d}} \mathrm{sv}, \mathrm{mN} / \mathrm{m}$ & Reference \\
\hline Water & 72.8 & 46.4 & 26.4 & {$[48]$} \\
$n$-hexane & 18.4 & 0.0 & 18.4 & \\
\hline
\end{tabular}

\subsection{Adhesion Tests}

The evaluation of adhesion between silver and underlayer polymer was analysed by a cross-cut test according to ASTM D3359-09, method B. The test sample was cut by a sharp razor blade with the cutting-edge angle between $15-30^{\circ} \mathrm{C}$. Cross-cut was made with 6 cuts by spacing $2 \mathrm{~mm}$ apart between each other. Adhesive tape was applied to the cross-cut zone and pulled off. A qualitative evaluation was carried out by referring to the standard classification of adhesion test result with the rate $0-5$ scale. ( 0 indicate poor adhesion and 5 excellent adhesion).

\section{Results and Discussion}

To investigate the working temperature of TPU, DSC analysis was conducted to measure the glass transition temperature $\left(T_{g}\right)$ and melting point $\left(T_{m}\right)$ as well as recrystallization temperature $\left(T_{r}\right)$. Figure 4 showed the typical DSC graph of TPU substrate. The glass transition for TPU exhibited at temperature $79.96^{\circ} \mathrm{C}$, and the melting of TPU observed to be at two different temperatures, which is $113.63^{\circ} \mathrm{C}$ and $156.62^{\circ} \mathrm{C}$. The appearance of $\mathrm{Tm}$ peak consecutively as temperature elevated potentially result from varies crystal structure, size of the domain, or different degree of order in crystalline structure [49-52]. The order of the presence of endotherm peaks indicated belongs to the hard segment of TPU. In addition, the peak of crystallization temperature $\left(T_{c}\right)$ also appeared at the high temperature of $229.62^{\circ} \mathrm{C}$. Meanwhile, the recrystallization ( $T_{\mathrm{rs}}$ ) event occurs when cooling to a temperature of $227.30^{\circ} \mathrm{C}$.

Figure 5 shows the sheet resistance decreases as temperature increases. The plotted graph shows the resistance was decreased from $152.72 \mathrm{~m} \Omega / \mathrm{sq}$ to $20.81 \mathrm{~m} \Omega / \mathrm{sq}$ when temperature was elevated from room temperature to $140^{\circ} \mathrm{C}$, respectively. The sheet resistance showed a sharp decline from room temperature to $60^{\circ} \mathrm{C}$, indicating the densification of silver particles was initiated. As temperature continuously elevated, the resistance keeps decreasing gradually until it reaches a value 
of $20.81 \mathrm{~m} \Omega / \mathrm{sq}$ at the highest temperature of $140^{\circ} \mathrm{C}$. At this temperature, the resistance is approximately around the value of silver in the previous study ranging between 0.01-0.04 $\Omega /$ sq at dry thickness $25 \mu \mathrm{m}$ of ink layer [22]. The study of the correlation of resistance with temperature had proven by many researchers [53-55]. The silver grain said to experienced grain diffusion path before densification when the temperature keeps elevating from lower to high temperature.

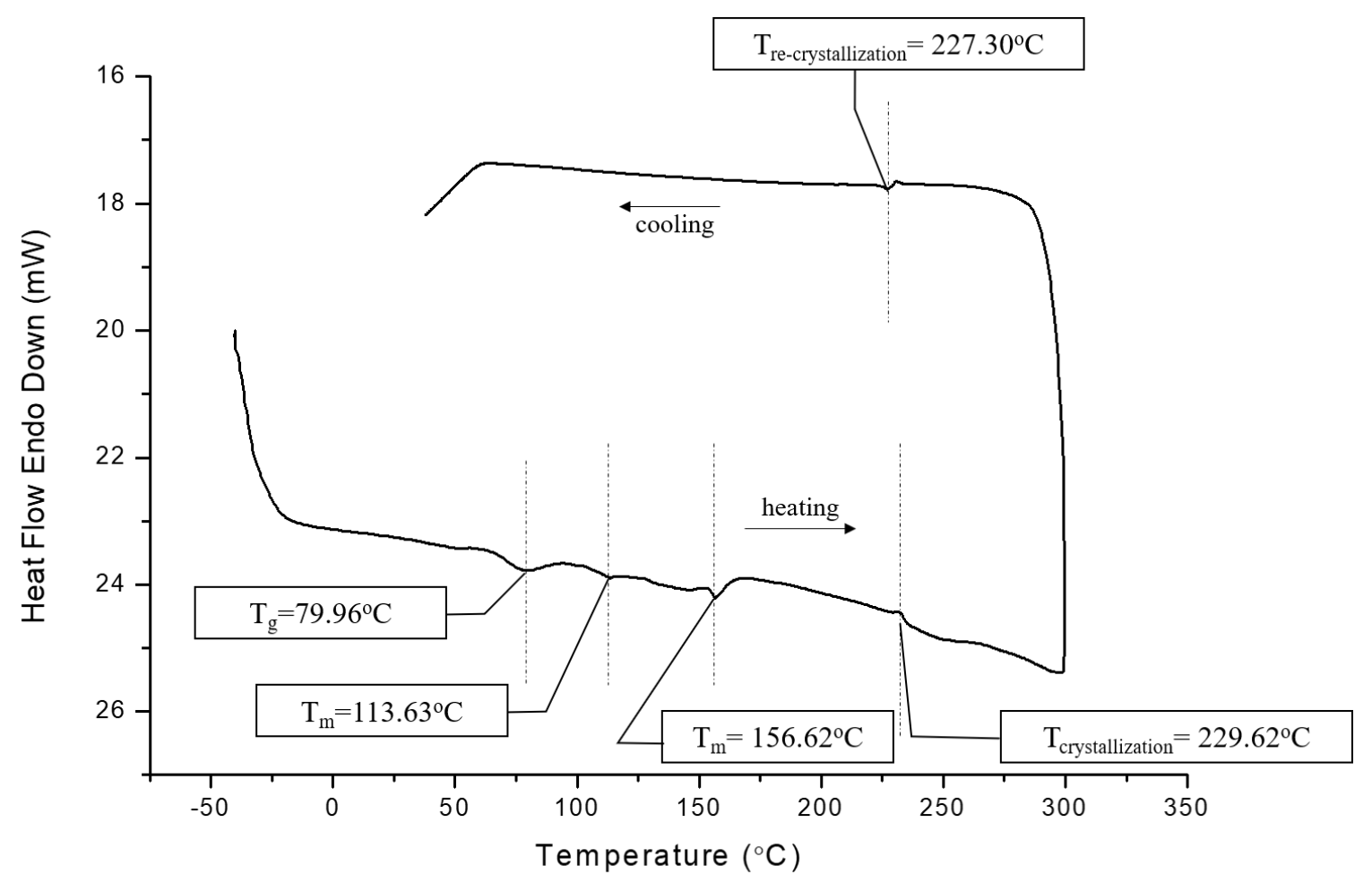

Fig. 4. DSC measurement for evaluate heating properties of underlayer polymer

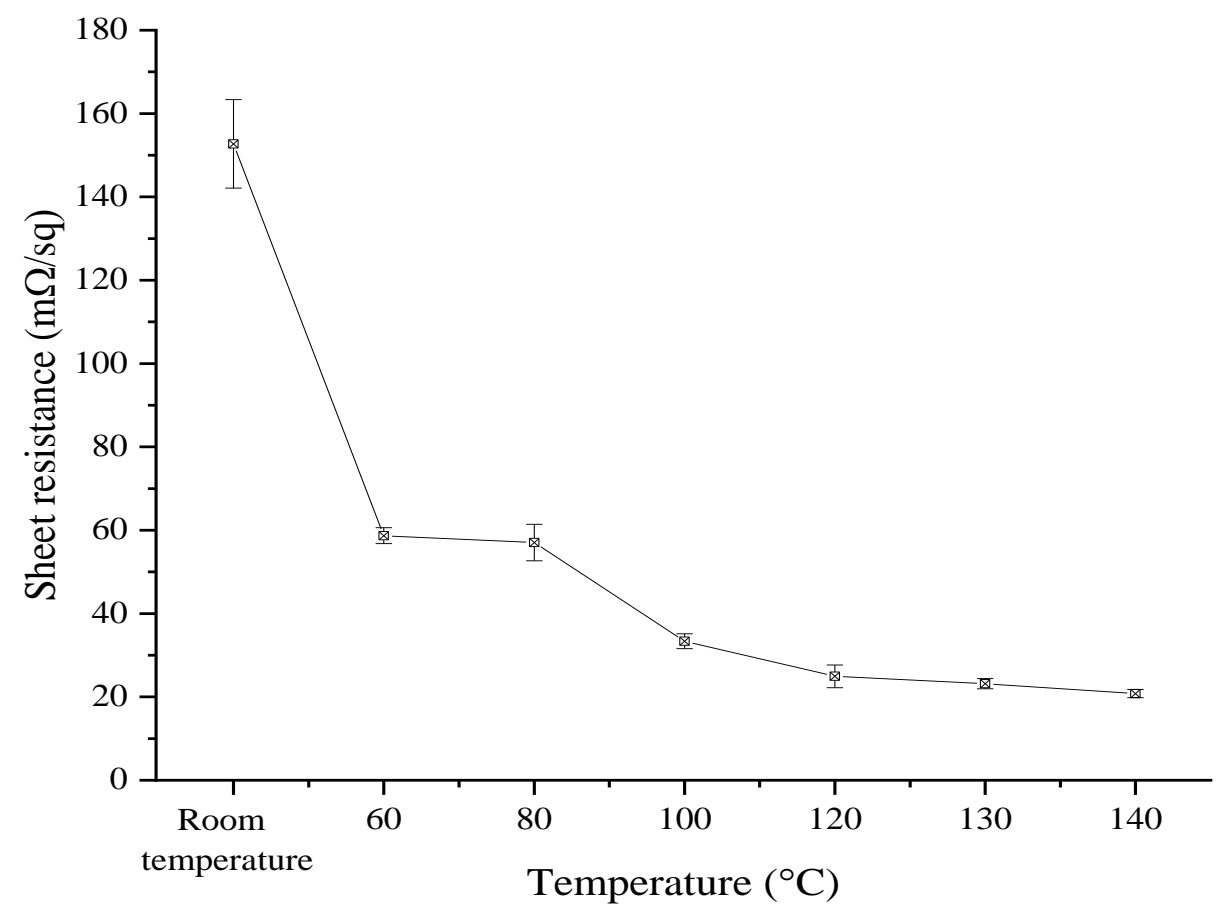

Fig. 5. Effect of temperature on the conductivity of silver 
The mechanism of nucleation and growth of grain takes place once each grain starts to contact each other when temperature elevates, as illustrated in Figure 6. At this rate, the distance between each grain is reduced respect to the elevation of temperature and initiate the diffusion or nucleation between particles. Diffusion of particles causing the necking to appear, which the necking structure becomes wider and thicker as the temperature continuously elevated. The particles further diffuse, when the centre of grains approaches one another concurrently reduced the grain boundary, resulting in the densification of particles to become bigger in size. At the highest curing temperature, the silver nanoparticles said to be well-interconnected to form a smooth structure. To have a better insight into this event, investigation of silver grain microstructure respected to temperature had been observed. Figure 7 displayed SEM micrograph of cross-sectional silver on the underlayer polymer at three different temperature: room temperature, $100^{\circ} \mathrm{C}$ and $120^{\circ} \mathrm{C}$. At room temperature, the presence of void between silver grains cause restriction of percolation path between grains, hence causing resistance to increase. To rule out the effect of curing temperature on the microstructure of grains, silver being cured the applied of heat. When temperature increases, the void between particles were reduced because densified structure occurred, hence this allowed the resistance to reduced respected to the elevated curing temperature.

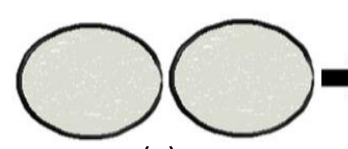

(a)

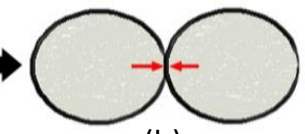

(b)

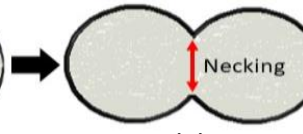

(c)

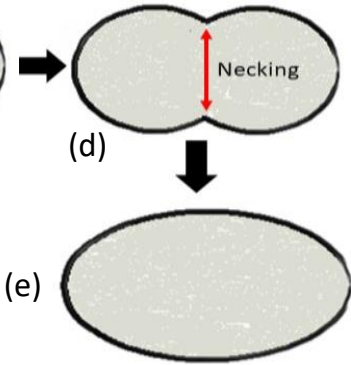

Fig. 6. The grain diffusion pathways respected to the elevation of temperature (a) silver grains reduced the distances between each other, (b) initiation of diffusion, (c) to (d) necking structure between grains become thicker and wider, (e) grain grow bigger after complete diffusion

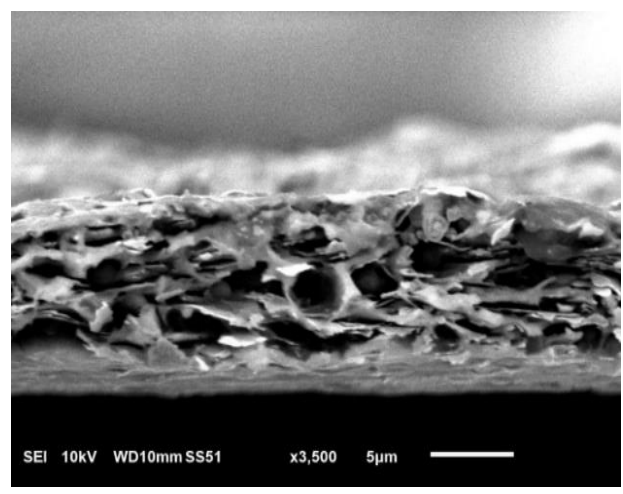

(a)

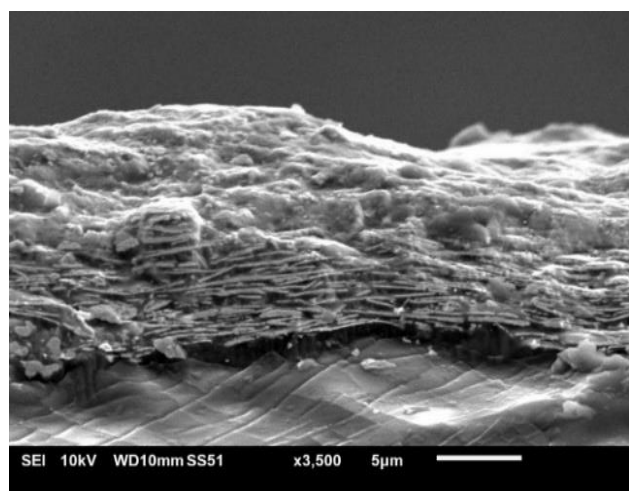

(b)

Fig. 7. SEM micrograph of printed silver cured at different temperature (a) room temperature and (b) $120^{\circ} \mathrm{C}$

To investigate the effect of temperature on the adhesion performance between silver and underlayer TPU, the curing of silver was done at different temperatures. Then, the adhesion performance of silver was measured based on cross-cut test according to ASTM D3359. According to Figure 8 , adhesion performance between silver and underlayer showed excellent performance in the range $4 \mathrm{~B}$ to $5 \mathrm{~B}$ when curing is performed at a temperature from $100^{\circ} \mathrm{C}$ to $140^{\circ} \mathrm{C}$ respectively. The 
adhesion rating place as $5 \mathrm{~B}$ due to the edges of the cut remains smooth and there no detachment of lattice square. Curing at the temperature beyond glass transition, $\mathrm{T}_{\mathrm{g}}$ of underlayer polymer $\left(79.96^{\circ} \mathrm{C}\right)$, the adhesion between silver and underlayer start giving excellent performance at this range of temperature rather than at temperature lower or same to $T_{g}$ of the underlayer polymer. From this result, we concluded that silver and TPU excellently adhered through the mechanism of intermixing between printed silver layer and underlayer TPU at the interface when cured at a temperature above $\mathrm{T}_{\mathrm{g}}$ of TPU. The intermixing result with the formation of interfused layer structure between silver and underlayer upon heating, as illustrated in Figure 8. For a better understanding, microstructure analysis was carried out to observe the interfused layer appearance. Figure 9 displays the micrograph of cross-sectional silver on underlayer TPU, which cured at different temperatures. It shows the interfusion of silver into polymer start to form and the gap between it also getting smaller when curing was beyond $\mathrm{T}_{\mathrm{g}}$ of the polymer. The cross-section of silver at room temperature, $60^{\circ} \mathrm{C}$ and $80^{\circ} \mathrm{C}$ shows the gap between silver and TPU can be seen clearly where act as contact resistance between materials. At temperature $100^{\circ} \mathrm{C}$, gap region was not totally disappeared, but the silver can be seen initiate to make a direct contact with the underlayer substrate. However, when the temperature was elevated up to $140^{\circ} \mathrm{C}$, the cross-sectional view showed the gap between silver and underlayer totally disappeared and direct contact as well as surface diffusion can be seen between silver and underlayer. Correspondingly, this occasion act as mechanical interlocking between two different materials which allowing strong adhesion. Similar findings found by Sekine et. al., which in their studies, the effect of surface energy and sintering temperature beyond $T_{g}$ showed a significant influence on the adhesion performance [56]. Sekine and co-researchers stated that sintering of silver at a temperature beyond $\mathrm{T}_{\mathrm{g}}$ and polymer with high surface energy play significant evaluation in generating good adhesion between silver and underlayer polymer.

Figure 10 and Table 2 show the change in the water contact angle on the TPU substrate as temperature change. The graph displays water contact angle increasing ranging from $95^{\circ}$ to $100.1^{\circ}$ while surface energy decreases from $15.28 \mathrm{mN} / \mathrm{m}$ to $13.05 \mathrm{mN} / \mathrm{m}$ when temperature increase from room temperature to $80^{\circ} \mathrm{C}$ respectively. This shows TPU exhibits hydrophobicity when temperature being heated up to $80^{\circ} \mathrm{C}$. In accordance with the present result, our previous study has demonstrated that the exposure of TPU to temperature up to $80^{\circ} \mathrm{C}$ lead toward increase in the hydrophobicity of the surface [57]. However, when temperature increase up to $140^{\circ} \mathrm{C}$, water contact angle gradually decreased to $81.0^{\circ}$ and at this temperature surface energy is at the highest $(24.34 \mathrm{mN} / \mathrm{m})$ which TPU said to be hydrophilic. The correlation between surface energy and water contact angle had been discussed by previous researchers [58,59]. Surface energy of solid is depend on the chemical composition and atomic arrangements on the surface for instance, surface restructuring, composition segregation can cause surface energy of solid to reduce hence cause the surface to be hydrophobic [58]. In addition, factor affecting contact angles of polymer surface discussed by the previous researcher including the dependence of temperature on contact angle [60]. He concluded as little or no effect of temperature on contact angles of the polymer when temperature increases from $20-180^{\circ} \mathrm{C}$.

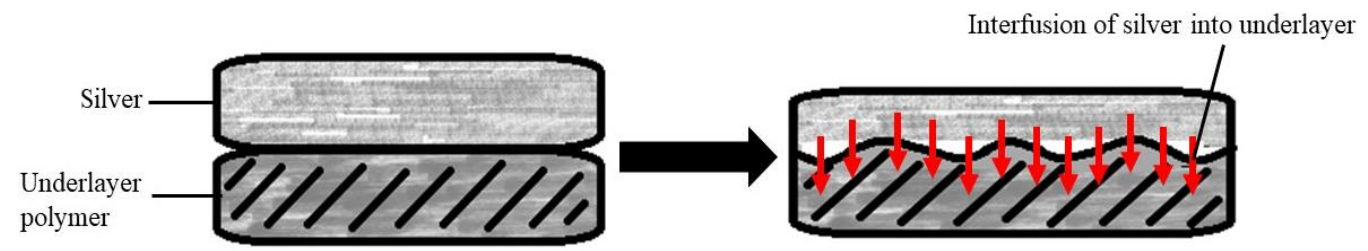

Fig. 8. Interfused layer formation between silver and underlayer when heating performs above $\mathrm{T}_{\mathrm{g}}$ of underlayer polymer 

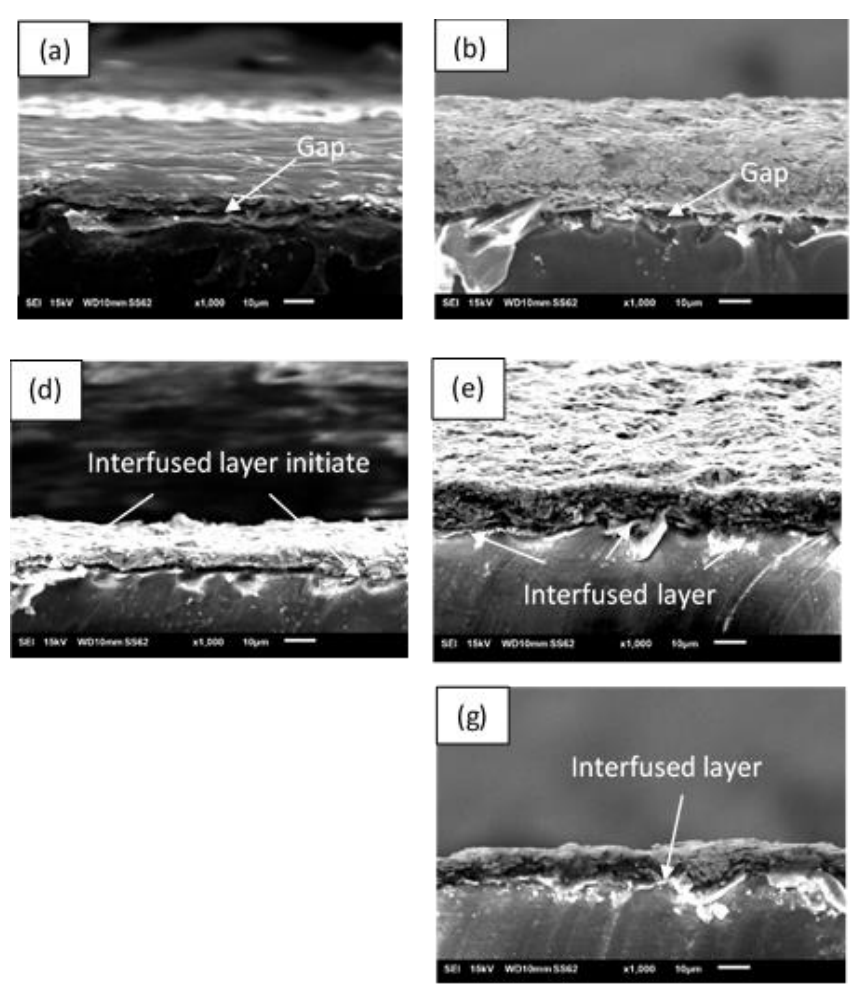
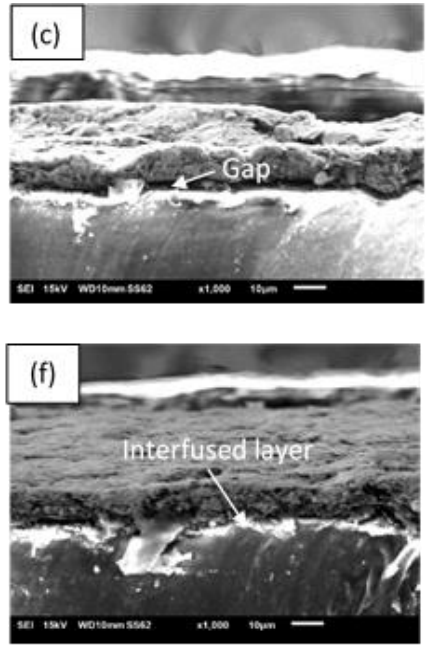

Fig. 9. SEM micrograph of cross-sectional silver on underlayer TPU at different temperature: (a) room temperature, (b) $60^{\circ} \mathrm{C}$, (c) $80^{\circ} \mathrm{C}$, (d) $100^{\circ} \mathrm{C}$, (e) $120^{\circ} \mathrm{C}$, (f) $130^{\circ} \mathrm{C}$ and $140^{\circ} \mathrm{C}$. When heating performed above $\mathrm{T}_{\mathrm{g}}$ of underlayer polymer, interfused layer formation between silver and underlayer start to appear and the gap become smaller

According to the plotted graph in Figure 10, surface energy increasing as the temperature elevated beyond the $\mathrm{T}_{\mathrm{g}}$ of TPU $\left(100^{\circ} \mathrm{C}, 120^{\circ} \mathrm{C}, 130^{\circ} \mathrm{C}\right.$ and $\left.140^{\circ} \mathrm{C}\right)$. This trend contradicts from the previous studies by showing dependency of temperature on the surface energy of polymer. To our knowledge, there is still lack in the detailed investigation of the temperature effect on the surface energy of polymer, hence study on $\mathrm{T}_{\mathrm{g}}$ behavior as a function of interfacial energy explained the event [61]. Thickness of polymer less than $100 \mathrm{~nm}$ showed apparent dependence of $\mathrm{T}_{\mathrm{g}}$ on the interfacial energy as higher the $T_{g}$ result from higher surface energy of polymer. However, in this study, the surface energy change due to temperature shows insignificant in determining the adhesiveness of printed silver on TPU. The TPU at room temperature has a higher surface energy of $15.28 \mathrm{mN} / \mathrm{m}$ exhibits poor adhesion with rating $\mathrm{OB}$ compared than TPU at $100^{\circ} \mathrm{C}$ with a surface energy of 14.13 $\mathrm{mN} / \mathrm{m}$ show excellent $4 \mathrm{~B}$ adhesion rating. In addition, it also displays the adhesion rating at curing temperature $120^{\circ} \mathrm{C}$ is $5 \mathrm{~B}$ with the surface energy, $15.72 \mathrm{mN} / \mathrm{m}$. The graph shows, even though the differences in surface energy at $120^{\circ} \mathrm{C}$ and room temperature is small $(0.44 \mathrm{mN} / \mathrm{m})$, the adhesion evaluation shows a big gap of adhesion rating. Therefore, we deduced that the surface energy of TPU did not play a significant role in the improvement of adhesion, instead of, the improvement of adhesion occurred throughout the curing process when exposed to temperature. 


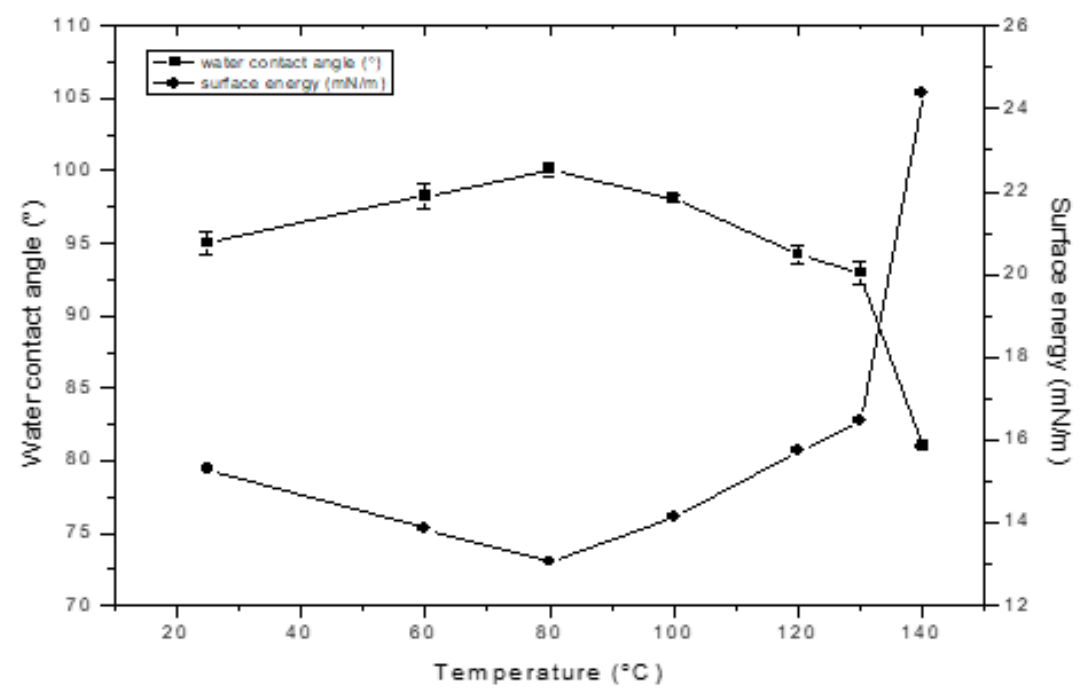

Fig. 10. Effect of temperature on the wettability and surface energy of substrate surface

Table 2

Contact angle and surface energy respected to temperature exposure

\begin{tabular}{lllllll}
\hline $\begin{array}{l}\text { Temperature } \\
\left({ }^{\circ} \mathrm{C}\right)\end{array}$ & $\mathrm{CA}_{\text {water }}\left(^{\circ}\right)$ & $\mathrm{CA}_{\mathrm{n} \text {-hexane }}\left(^{\circ}\right)$ & $\gamma_{\mathrm{sv}}(\mathrm{mN} / \mathrm{m})$ & $\gamma^{\mathrm{P}} \mathrm{sv}(\mathrm{mN} / \mathrm{m})$ & $\gamma^{\mathrm{d}} \mathrm{sv}(\mathrm{mN} / \mathrm{m})$ & $\begin{array}{l}\text { Adhesion } \\
\text { level }\end{array}$ \\
\hline $\begin{array}{l}\text { Room } \\
\text { temperature }\end{array}$ & $95.0 \pm 0.8$ & $77.1 \pm 0.6$ & 15.28 & 8.42 & 6.86 & OB \\
60 & $98.3 \pm 0.9$ & $73.0 \pm 0.6$ & 13.83 & 6.16 & 7.67 & $0 \mathrm{~B}$ \\
80 & $100.1 \pm 0.5$ & $73.0 \pm 0.8$ & 13.05 & 5.37 & 7.68 & $0 \mathrm{~B}$ \\
100 & $98.1 \pm 0.2$ & $70.1 \pm 0.9$ & 14.13 & 5.88 & 8.25 & $4 \mathrm{~B}$ \\
120 & $94.2 \pm 0.6$ & $76.7 \pm 0.1$ & 15.72 & 8.76 & 6.96 & $5 \mathrm{~B}$ \\
130 & $92.9 \pm 0.8$ & $70.4 \pm 0.9$ & 16.70 & 8.50 & 8.20 & $5 \mathrm{~B}$ \\
140 & $81.0 \pm 0.1$ & $69.3 \pm 0.9$ & 24.34 & 15.93 & 8.41 & $5 \mathrm{~B}$ \\
\hline
\end{tabular}

\section{Conclusions}

Throughout this study, temperature plays a significant role in giving a better electrical performance of silver conductivity as well as improving adhesion performance between silver and TPU underlayer. By increasing the temperature, the sheet resistance of the silver shows reduction as densification event of the silver grains allowed reduction of voids between the grains, hence allowed smooth electrical transfer within the silver. Temperature also contributes towards increase the wettability and surface energy of the substrate when the temperature exposed is beyond the $T_{g}$ of the TPU. However, the surface energy changes did not significantly contribute towards the adhesiveness performance, instead of adhesion improved throughout the curing process of conductive ink at different temperature. The improvement of adhesion respected to temperature proved through interfusion region developed between silver and TPU underlayer which act as mechanical interlocking. The finding of this study emphasized the understanding and information of the influence of temperature when TPU used as underlayer substrate in developing reliable flexible printed circuit. 


\section{Acknowledgement}

The author gratefully acknowledges the fellowship scheme (UTeM Zamalah 2.0 scheme) by Universiti Teknikal Malaysia Melaka, Malaysia and financial support from Universiti Teknikal Malaysia Melaka and The Ministry of Education, Malaysia (MoE) under Fundamental Research Grant Scheme (FRGS), grant no.: FRGS/2018/FKM-CARE/F00366.

\section{References}

[1] Baibergenova, Akerke, Rustam Kudyakov, Michael Zdeb, and David O. Carpenter. "Low birth weight and residential proximity to PCB-contaminated waste sites." Environmental Health Perspectives 111, no. 10 (2003): 1352-1357. https://doi.org/10.1289/ehp.6053

[2] Fu, Jianjie, Haiyan Zhang, Aiqian Zhang, and Guibin Jiang. "E-waste Recycling in China: A Challenging Field." Environmental Science and Technology 52 (2018): 6727-6728.

https://doi.org/10.1021/acs.est.8b02329

[3] Esenduran, Gökçe, Atalay Atasu, and Luk N. Van Wassenhove. "Valuable e-waste: Implications for extended producer responsibility." IISE Transactions 51, no. 4 (2019): 382-396.

https://doi.org/10.1080/24725854.2018.1515515

[4] Grant, Kristen, Fiona C. Goldizen, Peter D. Sly, Marie-Noel Brune, Maria Neira, Martin van den Berg, and Rosana E. Norman. "Health consequences of exposure to e-waste: a systematic review." The Lancet Global Health 1, no. 6 (2013): e350-e361.

https://doi.org/10.1016/S2214-109X(13)70101-3

[5] Baldé, Cornelis P., Vanessa Forti, Vanessa Gray, Ruediger Kuehr, and Paul Stegmann. "The global e-waste monitor 2017: Quantities, flows and resources." United Nations University, International Telecommunication Union, and International Solid Waste Association (2017).

[6] Burke, Maria. "The gadget scrap heap: As we constantly upgrade and replace our numerous electronic devices, the rubbish tip of forgotten, out-of-date equipment continues to grow." Chemistry World 4, no. 6 (2007): 44-49.

[7] Huang, Kui, Jie Guo, and Zhenming Xu. "Recycling of waste printed circuit boards: A review of current technologies and treatment status in China." Journal of Hazardous Materials 164, no. 2-3 (2009): 399-408.

https://doi.org/10.1016/i.jhazmat.2008.08.051

[8] Zhou, Yihui, and Keqiang Qiu. "A new technology for recycling materials from waste printed circuit boards." Journal of Hazardous Materials 175, no. 1-3 (2010): 823-828. https://doi.org/10.1016/i.jhazmat.2009.10.083

[9] IPC. "Global PCB Production's High Growth in 2017; Up 14\%." I.Connect $007,2018$. http://pcb.iconnect007.com/index.php/article/113511/global-pcb-productions-high-growth-in-2017-up14/113514/?skin=pcb.

[10] Directive, E. U. "96/EC of the European Parliament and of the Council of 27 January 2003 on waste electrical and electronic equipment (WEEE)." Official Journal of the European Union L 37 (2002): 24-38.

[11] Union, Better Regulation for Growth and Jobs in the European. "Communication from the Commission to the Council and the European Parliament." COM (2005) 97 Final, Commission of the European Communities (2005).

[12] Sinha-Khetriwal, Deepali, Philipp Kraeuchi, and Markus Schwaninger. "A comparison of electronic waste recycling in Switzerland and in India." Environmental Impact Assessment Review 25, no. 5 (2005): 492-504. https://doi.org/10.1016/i.eiar.2005.04.006

[13] Yoshida, Aya, Tomohiro Tasaki, and Atsushi Terazono. "Material flow of used PCs in Japan." In Proceedings of the 2007 IEEE International Symposium on Electronics and the Environment, pp. 46-51. 2007. https://doi.org/10.1109/ISEE.2007.369100

[14] Zoeteman, Bastiaan CJ, Harold R. Krikke, and Jan Venselaar. "Handling WEEE waste flows: on the effectiveness of producer responsibility in a globalizing world." The International Journal of Advanced Manufacturing Technology 47, no. 5-8 (2010): 415-436. https://doi.org/10.1007/s00170-009-2358-3

[15] Kummer, Katharina. "The international regulation of transboundary traffic in hazardous wastes: The 1989 Basel Convention." International \& Comparative Law Quarterly 41, no. 3 (1992): 530-562. https://doi.org/10.1093/iclqai/41.3.530

[16] Younis, Mohammad Ibrahim. "Modeling and simulation of microelectromechanical systems in multi-physics fields." PhD diss., Virginia Tech, 2004.

[17] Zhang, Guo-Qi, W. D. Van Driel, and X. J. Fan. Mechanics of Microelectronics. Vol. 141. Springer Science \& Business Media, 2006. 
https://doi.org/10.1007/1-4020-4935-8

[18] Coombs, Clyde F., and Happy T. Holden. Printed Circuits Handbook. Vol. 1. New York, USA: McGraw-Hill, 2001.

[19] Macleod, Peter. A review of flexible circuit technology and its applications. PRIME Faraday Partnership, 2002.

[20] Mohammed, Anwar, and Michael Pecht. "A stretchable and screen-printable conductive ink for stretchable electronics." Applied Physics Letters 109, no. 18 (2016): 184101. https://doi.org/10.1063/1.4965706

[21] Chou, Kan Sen, Kuo Cheng Kui Huang, Hsien Hsuen Lee, Ulrich S. Schubert, Jolke Perelaer, Antonius W. M. De Laat, Chris E. Hendriks et al. "Electrically Conductive Inks for Inkjet Printing." Journal of Materials Chemistry 5 no. 7 (2007): 157-70.

[22] Merilampi, Sari, T. Laine-Ma, and Pekka Ruuskanen. "The characterization of electrically conductive silver ink patterns on flexible substrates." Microelectronics Reliability 49, no. 7 (2009): 782-790. https://doi.org/10.1016/i.microrel.2009.04.004

[23] Kim, Jayoung, Rajan Kumar, Amay J. Bandodkar, and Joseph Wang. "Advanced materials for printed wearable electrochemical devices: A review." Advanced Electronic Materials 3, no. 1 (2017): 1600260. https://doi.org/10.1002/aelm.201600260

[24] Liang, Jiajie, Yan Wang, Yi Huang, Yanfeng Ma, Zunfeng Liu, Jinming Cai, Chendong Zhang, Hongjun Gao, and Yongsheng Chen. "Electromagnetic interference shielding of graphene/epoxy composites." Carbon 47, no. 3 (2009): 922-925. https://doi.org/10.1016/i.carbon.2008.12.038

[25] Sandler, JKWea, J. E. Kirk, I. A. Kinloch, M. S. P. Shaffer, and A. H. Windle. "Ultra-low electrical percolation threshold in carbon-nanotube-epoxy composites." Polymer 44, no. 19 (2003): 5893-5899. https://doi.org/10.1016/S0032-3861(03)00539-1

[26] Lin, Yung-Sen, and Sheng-Shiang Chiu. "Electrical properties of copper-filled electrically conductive adhesives and pressure-dependent conduction behavior of copper particles." Journal of Adhesion Science and Technology 22, no. 14 (2008): 1673-1697. https://doi.org/10.1163/156856108X320537

[27] Ho, Li-Ngee, Hiroshi Nishikawa, Naohide Natsume, Tadashi Takemoto, Koichi Miyake, Masakazu Fujita, and Koyu Ota. "Effects of trace elements in copper fillers on the electrical properties of conductive adhesives." Journal of Electronic Materials 39, no. 1 (2010): 115-123. https://doi.org/10.1007/s11664-009-0946-5

[28] Lee, Hsien-Hsuen, Kan-Sen Chou, and Zong-Whie Shih. "Effect of nano-sized silver particles on the resistivity of polymeric conductive adhesives." International Journal of Adhesion and Adhesives 25, no. 5 (2005): 437-441. https://doi.org/10.1016/j.ijadhadh.2004.11.008

[29] Ahmad, Intan Fatihah, Ghazali Omar, and Mohd Azli Salim. "Extrinsic Activation Energy for Enhanced Solid-State Metallic Diffusion for Electrical Conductive Ink." Journal of Advanced Research in Fluid Mechanics and Thermal Sciences 50, no. 1 (2018): 32-39.

[30] Magdassi, Shlomo. "Ink requirements and formulations guidelines." The Chemistry of Inkjet Inks. MAGDASSI, S. Eds (2010): 19-42. https://doi.org/10.1142/9789812818225 0002

[31] Suganuma, Katsuaki. Introduction to Printed Electronics. Vol. 74. Springer Science \& Business Media, 2014.

[32] Buffat, Ph, and Jean Pierre Borel. "Size effect on the melting temperature of gold particles." Physical Review A 13, no. 6 (1976): 2287. https://doi.org/10.1103/PhysRevA.13.2287

[33] Ding, Lifeng, Ruslan L. Davidchack, and Jingzhe Pan. "A molecular dynamics study of sintering between nanoparticles." Computational Materials Science 45, no. 2 (2009): 247-256.

https://doi.org/10.1016/j.commatsci.2008.09.021

[34] Kamyshny, Alexander, Joachim Steinke, and Shlomo Magdassi. "Metal-based inkjet inks for printed electronics." The Open Applied Physics Journal 4, no. 1 (2011): 19-36. https://doi.org/10.2174/1874183501104010019

[35] Tobjörk, Daniel, and Ronald Österbacka. "Paper electronics." Advanced Materials 23, no. 17 (2011): 1935-1961. https://doi.org/10.1002/adma.201004692

[36] Lee, Jaehong, Hyukho Kwon, Jungmok Seo, Sera Shin, Ja Hoon Koo, Changhyun Pang, Seungbae Son et al. "Conductive fiber-based ultrasensitive textile pressure sensor for wearable electronics." Advanced Materials 27, no. 15 (2015): 2433-2439. https://doi.org/10.1002/adma.201500009

[37] Fuller, Sawyer B., Eric J. Wilhelm, and Joseph M. Jacobson. "Ink-jet printed nanoparticle microelectromechanical systems." Journal of Microelectromechanical Systems 11, no. 1 (2002): 54-60. 
https://doi.org/10.1109/84.982863

[38] Cruz, S., L. A. Rocha, and J. C. Viana. "Enhanced printability of thermoplastic polyurethane substrates by silica particles surface interactions." Applied Surface Science 360 (2016): 198-206.

https://doi.org/10.1016/i.apsusc.2015.10.094

[39] Cruz, Sílvia, Luís A. Rocha, and Júlio C. Viana. "Piezo-resistive behaviour at high strain levels of PEDOT: PSS printed on a flexible polymeric substrate by a novel surface treatment." Journal of Materials Science: Materials in Electronics 28, no. 3 (2017): 2563-2573.

https://doi.org/10.1007/s10854-016-5832-3

[40] Chiang, Chia-Chu, Chou-Ching K. Lin, and Ming-Shuang Ju. "An implantable capacitive pressure sensor for biomedical applications." Sensors and Actuators A: Physical 134, no. 2 (2007): 382-388.

https://doi.org/10.1016/i.sna.2006.06.007

[41] Cheng, M-Y., C-L. Lin, and Y-J. Yang. "Tactile and shear stress sensing array using capacitive mechanisms with floating electrodes." In 2010 IEEE 23rd International Conference on Micro Electro Mechanical Systems (MEMS), pp. 228-231. IEEE, 2010.

https://doi.org/10.1109/MEMSYS.2010.5442525

[42] Suzuki, Masato, Tomokazu Takahashi, and Seiji Aoyagi. "Flexible tactile sensor using polyurethane thin film." Micromachines 3, no. 2 (2012): 315-324.

https://doi.org/10.3390/mi3020315

[43] Caglar, Umur, Kimmo Kaija, and Pauliina Mansikkamaki. "Analysis of mechanical performance of silver inkjetprinted structures." In 2008 2nd IEEE International Nanoelectronics Conference, pp. 851-856. IEEE, 2008. https://doi.org/10.1109/INEC.2008.4585617

[44] Silvain, J. F., A. Veyrat, and J. J. Ehrhardt. "Effect of the temperature on the adhesion and the morphology of thin metal films evaporated on polyethylene terephthalate." Thin Solid Films 221, no. 1-2 (1992): 114-119.

https://doi.org/10.1016/0040-6090(92)90803-J

[45] Sekine, Tomohito, Hideaki Ikeda, Akifumi Kosakai, Kenjiro Fukuda, Daisuke Kumaki, and Shizuo Tokito. "Improvement of mechanical durability on organic TFT with printed electrodes prepared from nanoparticle ink." Applied Surface Science 294 (2014): 20-23. https://doi.org/10.1016/i.apsusc.2013.12.168

[46] Jiu, Jinting, Tohru Sugahara, Masaya Nogi, Teppei Araki, Katsuaki Suganuma, Hiroshi Uchida, and Kenji Shinozaki. "High-intensity pulse light sintering of silver nanowire transparent films on polymer substrates: the effect of the thermal properties of substrates on the performance of silver films." Nanoscale 5, no. 23 (2013): 11820-11828. https://doi.org/10.1039/c3nr03152g

[47] Joo, Sungchul, and Daniel F. Baldwin. "Adhesion mechanisms of nanoparticle silver to substrate materials: identification." Nanotechnology 21, no. 5 (2009): 055204. https://doi.org/10.1088/0957-4484/21/5/055204

[48] Rulison, Christopher. "So you want to measure surface energy." Charlotte NC (cf. p. 99) (1999).

[49] Eceiza, A., M. D. Martin, K. De La Caba, G. Kortaberria, N. Gabilondo, M. A. Corcuera, and I. Mondragon. "Thermoplastic polyurethane elastomers based on polycarbonate diols with different soft segment molecular weight and chemical structure: mechanical and thermal properties." Polymer Engineering \& Science 48, no. 2 (2008): 297-306. https://doi.org/10.1002/pen.20905

[50] Hesketh, T. R., J. W. C. Van Bogart, and Stuart L. Cooper. "Differential scanning calorimetry analysis of morphological changes in segmented elastomers." Polymer Engineering \& Science 20, no. 3 (1980): 190-197. https://doi.org/10.1002/pen.760200304

[51] Speckhard, T. A., P. E. Gibson, S. L. Cooper, V. S. C. Chang, and J. P. Kennedy. "Properties of polyisobutylene polyurethane block copolymers: 2. Macroglycols produced by the 'inifer'technique." Polymer 26, no. 1 (1985): 5569. https://doi.org/10.1016/0032-3861(85)90057-6

[52] Van Bogart, J. W. C., D. A. Bluemke, and Stuart L. Cooper. "Annealing-induced morphological changes in segmented elastomers." Polymer 22, no. 10 (1981): 1428-1438. https://doi.org/10.1016/0032-3861(81)90250-0

[53] Greer, Julia R., and Robert A. Street. "Thermal cure effects on electrical performance of nanoparticle silver inks." Acta Materialia 55, no. 18 (2007): 6345-6349. https://doi.org/10.1016/i.actamat.2007.07.040

[54] Perelaer, Jolke, Chris E. Hendriks, Antonius WM de Laat, and Ulrich S. Schubert. "One-step inkjet printing of conductive silver tracks on polymer substrates." Nanotechnology 20, no. 16 (2009): 165303. https://doi.org/10.1088/0957-4484/20/16/165303 
[55] Nie, Xiaolei, Hong Wang, and Jing Zou. "Inkjet printing of silver citrate conductive ink on PET substrate." Applied Surface Science 261 (2012): 554-560.

https://doi.org/10.1016/j.apsusc.2012.08.054

[56] Sekine, Tomohito, Kenjiro Fukuda, Daisuke Kumaki, and Shizuo Tokito. "Enhanced adhesion mechanisms between printed nano-silver electrodes and underlying polymer layers." Nanotechnology 26, no. 32 (2015): 321001. https://doi.org/10.1088/0957-4484/26/32/321001

[57] Jasmee, Solehah, Ghazali Omar, N. A. B. Masripan, Anita Akmar Kamarolzaman, A. S. Ashikin, and F. Che Ani. "Hydrophobicity performance of polyethylene terephthalate (PET) and thermoplastic polyurethane (TPU) with thermal effect." Materials Research Express 5, no. 9 (2018): 096304. https://doi.org/10.1088/2053-1591/aad81e

[58] Shang, Huamei M., Ying Wang, Kenji Takahashi, Guozhong Z. Cao, Dan Li, and Y. N. Xia. "Nanostructured superhydrophobic surfaces." Journal of Materials Science 40, no. 13 (2005): 3587-3591. https://doi.org/10.1007/s10853-005-2892-9

[59] Kalin, M., and M. Polajnar. "The wetting of steel, DLC coatings, ceramics and polymers with oils and water: The importance and correlations of surface energy, surface tension, contact angle and spreading." Applied Surface Science 293 (2014): 97-108.

https://doi.org/10.1016/i.apsusc.2013.12.109

[60] Wu, Souheng. "Surface and interfacial tensions of polymer melts. II. Poly (methyl methacrylate), poly ( $\mathrm{n}$-butyl methacrylate), and polystyrene." The Journal of Physical Chemistry 74, no. 3 (1970): 632-638. https://doi.org/10.1021/j100698a026

[61] Fryer, David S., Richard D. Peters, Eui Jun Kim, Jeanne E. Tomaszewski, Juan J. de Pablo, Paul F. Nealey, Chris C. White, and Wen-li Wu. "Dependence of the glass transition temperature of polymer films on interfacial energy and thickness." Macromolecules 34, no. 16 (2001): 5627-5634.

https://doi.org/10.1021/ma001932q 